\title{
Dental Treatment and Quantum Mechanics
}

\author{
Yoshiro Fujii \\ Shin-Kobe Dental Clinic, Kobe, Japan \\ Email: shin-kobe-dentalclinic@s9.dion.ne.jp
}

How to cite this paper: Fujii, Y. (2021) Dental Treatment and Quantum Mechanics. Case Reports in Clinical Medicine, 10 177-184.

https://doi.org/10.4236/crcm.2021.107022

Received: June 4, 2021

Accepted: July 6, 2021

Published: July 9, 2021

Copyright $\odot 2021$ by author(s) and Scientific Research Publishing Inc. This work is licensed under the Creative Commons Attribution International License (CC BY 4.0).

http://creativecommons.org/licenses/by/4.0/

\begin{abstract}
In clinical practice, dentists sometimes encounter phenomena that cannot be explained by common medical concepts; for example, patients' bodily symptoms immediately improved after adjusting a denture that was not even inside their mouth, by extracting an infected tooth, and by bringing medicine close to the body. Although it seems difficult to completely elucidate the mechanism through modern medicine, it can be explained using quantum mechanics if it is assumed that symptoms appear because of the pathological waves emitted by the afflicted area of the body. The quantum, the smallest unit of matter composition, exhibits wave-particle duality. The fact that symptoms can be improved simply by bringing dentures or medicines closer to the body indicates that the waves emitted by dentures or medicine interfere with the pathological waves. Thus, the pathological waves are deformed and lead to a change in symptoms. In this way, quantum theory can explain phenomena that are difficult to elucidate in conventional medicine, which are encountered in daily clinical practice. Using biological reactions, unsolved problems in quantum mechanics, such as measurement problems, can be solved.
\end{abstract}

\section{Keywords}

Dental Treatment, Quantum Mechanics, Wave Interference, The Bi-Digital O-Ring Test, Shoulder Impingement Syndrome

\section{Introduction}

The author has spent a long time studying the relationship between dentistry and the whole body. These two systems are interdependent, and in clinical cases, symptoms such as joint dysregulation: low back pain, stiff shoulders, hip joint dysregulation [1] [2] [3] [4], dermatitis [5] [6], and electromagnetic hypersensitivity [7] [8] [9] [10] [11]. However, because such complaints sometimes improve quickly after reforming a denture that has been removed from their 
mouth, after extracting an infected tooth, or by bringing the medicine closer to the body [12], the mechanisms underlying these observations cannot be fully explained by conventional medicine that many scientists and practitioners commonly believe in. It is assumed that dentures and drugs have no effect unless they are taken into the body. And, even if an infected tooth is extracted, many bacteria existing in the body cannot be immediately removed.

For a different perspective, the author has turned to the quantum mechanical approach. Quantum mechanics mainly describes microlevel physical phenomena, such as elementary particles, atoms, molecules, or electrons [13] [14]. Because the body is also composed of these elementary particles, it can be considered to be influenced by quantum phenomena. Quanta exhibit wave-particle duality, i.e., every quantum entity can be described as either a particle or a wave. When two or more waves are combined, wave interference occurs [15]. Thus, this makes it possible to explain the aforementioned phenomena if one assumes that the symptoms are caused by the pathological waves generated by the afflicted site of the body.

\section{Case Studies}

\subsection{Case 1}

Subject 1: A woman in her 70s

Chief complaint: She had difficulty in raising her left arm because of pain.

Medical history: Pain in the upper left arm was observed when raising her arm since 5 days ago and the pain gradually worsened.

Findings at initial visit: Partial dentures were located in the upper and lower jaws, and she had no discomfort or inconvenience with regard to the dentures. She had difficulty in raising her left limb because of pain (Figure 1).

Treatment: Her upper removable partial denture was removed and adjusted using the Bi-Digital O-Ring Test [16] [17].

Result: Although the denture was outside her body, her pain disappeared during adjustment (Figure 2). The denture was returned to her oral cavity and used as usual in her daily life. Her prognosis was good even after 1 week (Figure 3). Prognosis has been good for over a year.

Discussion of this case

It is possible that the waves emitted by the adjusted denture interfered with the pathological waves emitted by the afflicted area (i.e., her left upper limb). These were thought to be the cause of pain when raising her left limb. In this case, the author assumed the pathological waves might have been deformed by interfering with the waves emitted by the denture, the pathogenicity of the pathological waves decreased, thus alleviating her symptom.

\subsection{Case 2}

Subject 2: A woman in her 70s

Chief complaint: She had difficulty in moving her head because of neck pain. 


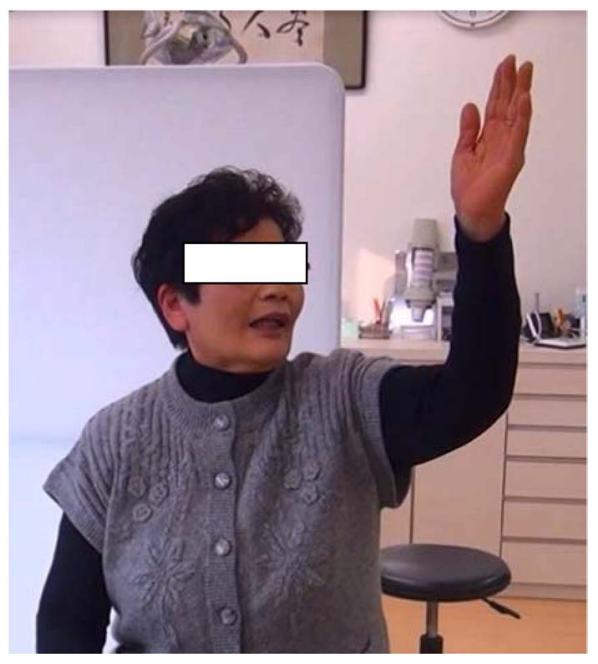

Figure 1. Findings at the first visit: Subject 1 had difficulty raising her left arm because of pain.

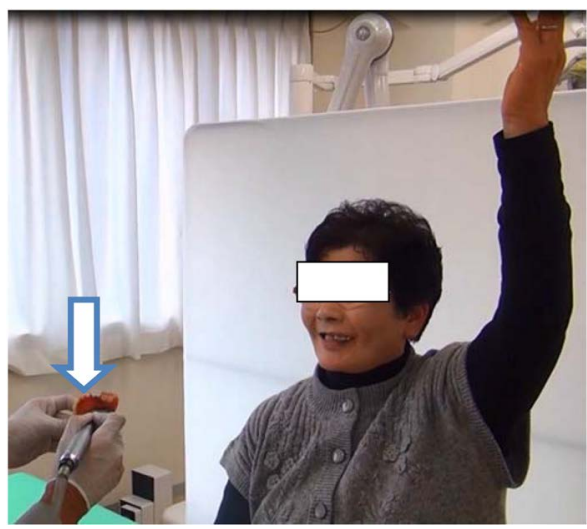

Figure 2. By adjusting her upper partial denture outside her body (arrow), subject 1's pain disappeared.

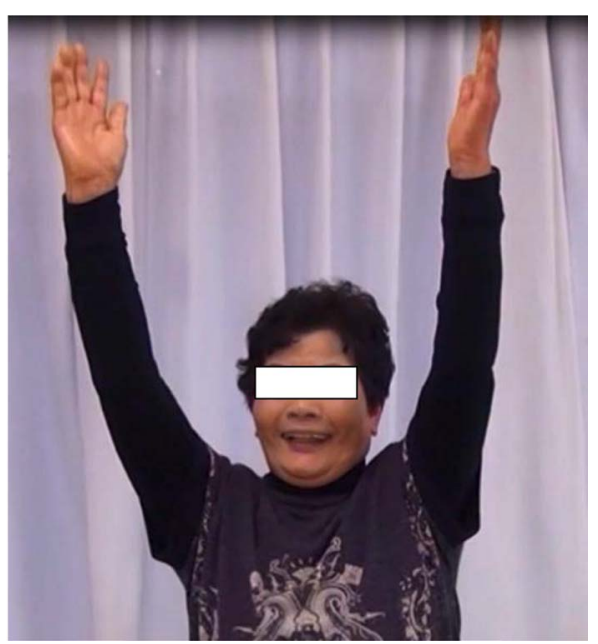

Figure 3. Findings 1 week after denture adjustment. Subject 1 had a good prognosis. 
Treatment and result: When her removable partial denture was adjusted outside her body as in the first case, her neck pain disappeared. The denture was returned to her oral cavity and used as usual, and she had a good prognosis.

A YouTube video, "Denture adjustment outside the body" showing some of the details of cases 1 and 2 can be viewed at https://www.youtube.com/watch?v=xFzv09sUWSA (accessed on April 1, 2021).

\subsection{Case 3}

Subject 3: A 72-year-old woman

Chief complaint: She had difficulty raising her right arm because of pain (Figure 4).

Medical history: The woman had suffered from difficulty in raising her arm because of her pain since 1.5 months ago. She was diagnosed with shoulder impingement syndrome and had received a nerve-block injection twice. These treatments merely temporarily relieved her pain without improving the mobility of her upper limb.

Findings at the first visit: Her right upper first premolar had fractured and caused local inflammation as seen in a CT image (Figure 5). Antibiotics were selected according to the Bi-Digital O-Ring Test [16] [17] and brought close to the region of the infection, because of which her systemic symptoms reduced, and she could easily raise her arm (Figure 6). When the antibiotics were moved away from her body, the symptoms reoccurred.

Treatment: Her upper right first premolar was extracted (Figure 7).

Result: She could raise her arm immediately after the infected tooth was extracted and she no longer experienced shoulder impingement or pain (Figure 8). Three years later, she still had a good prognosis without any medical treatment.

The YouTube video "Dental treatment for shoulder impingement syndrome" shows the details for case 3 . It can be viewed at https://www.youtube.com/watch? $\mathrm{v}=\mathrm{mdM} 2 \mathrm{eilSO} 4 \mathrm{~g} \& \mathrm{app}=$ desktop (accessed on August 1, 2020).

Discussion of this case

Shoulder impingement syndrome is a common condition involving pain and dysfunction of the afflicted shoulder. Its etiology can be multifactorial due to the interplay between intrinsic and extrinsic factors [18] [19]. In this case, it can be assumed that the pathological waves emitted by the infected first premolar and the right shoulder joint combined to cause her symptoms. Then, the symptoms improved when the antibiotics were brought close to her face because the pathological waves were interfered with those emitted by the antibiotic. Thus, the form of the pathological wave may have changed. After extracting her premolar, the original pathological waves disappeared, thus eliminating the symptoms.

This study shows that even when medicines exist outside of the body, they can have a marked effect on joint mobility. Generally, drugs and dentures are said to be ineffective in modern medicine unless they are taken into the body; however, 
in this case, it was only necessary for the medications to be close to the body [12].

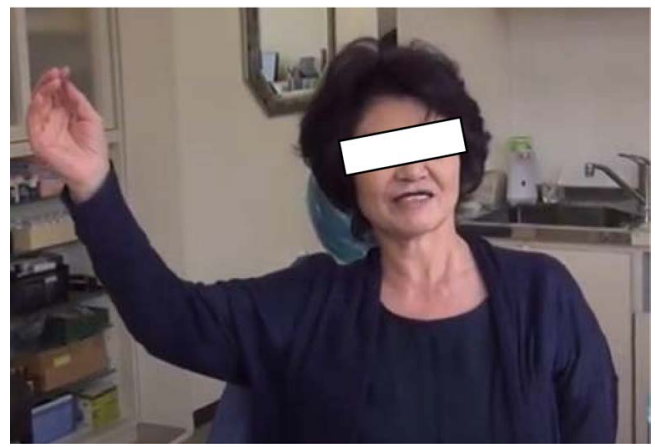

Figure 4. Subject 3 had difficulty raising her right arm because of pain.

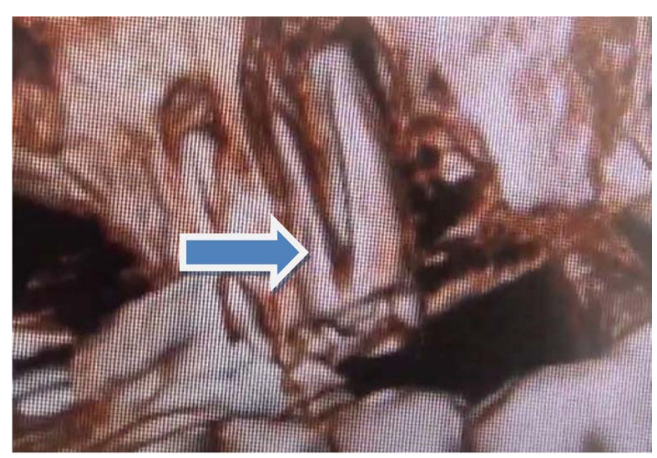

Figure 5. CT image showing that Subject 3's right upper first premolar had fractured (arrow), causing local inflammation.

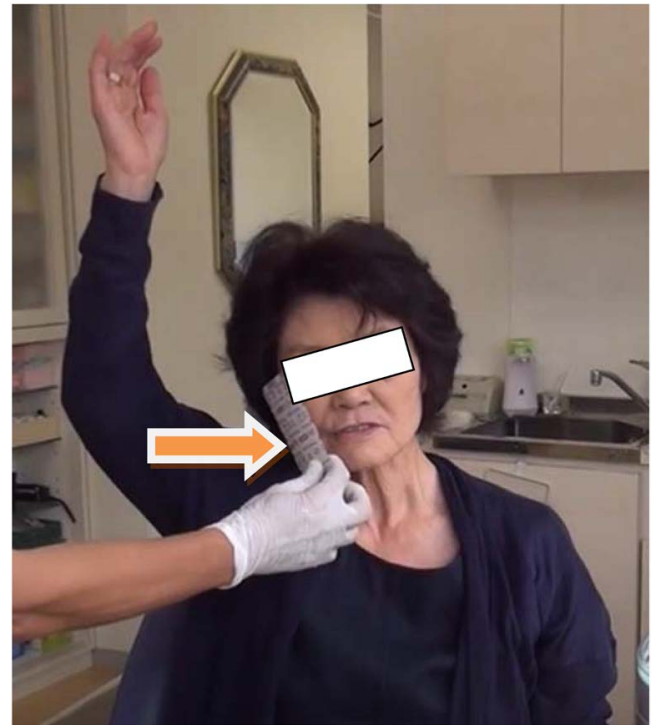

Figure 6. When antibiotics (arrow) were brought close to the area of infection, her systemic symptoms were reduced and she could raise her arm easily. 


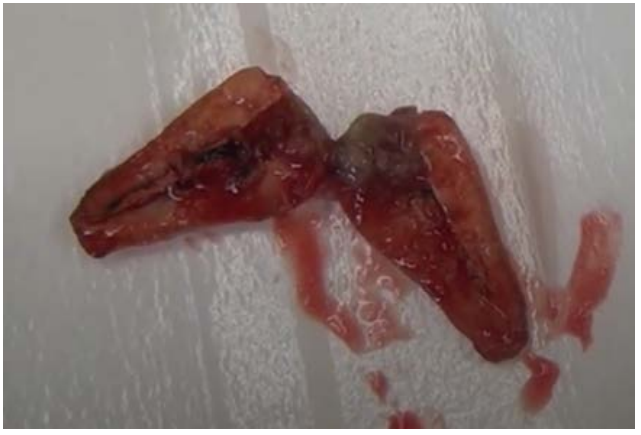

Figure 7. Subject 3's upper right first premolar was extracted.

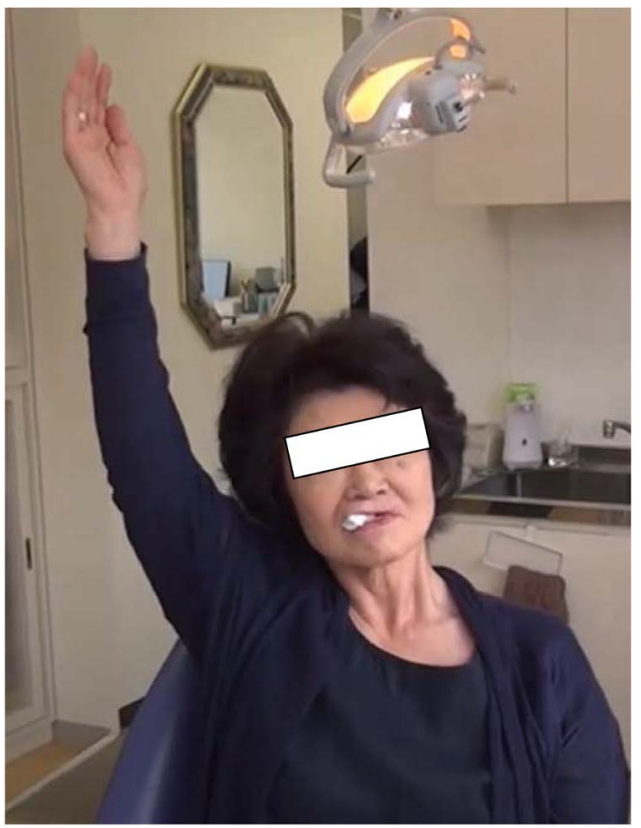

Figure 8. Subject 3 could easily raise her arm immediately after extraction of the tooth, no longer experienced shoulder impingement, and no longer felt pain.

\section{Discussion}

Quantum mechanics forms the basis of modern physics along with the general relativity theory. It mainly describes microscopic physical phenomena, such as molecules, atoms, or the elementary particles that compose them. Quantum mechanics analyzes elementary particles, the smallest constituent units of matter [14]; naturally, if the properties of the minimum constituent units of a substance change, the properties of the human body also change. The basis of quantum mechanics is that elementary particles exhibit a wave-particle duality [15].

We may sometimes experience situations in clinical practice that cannot be completely explained by conventional modern medicine. Although it appears difficult to elucidate the mechanism behind such phenomena, it can be explained using quantum mechanics if the symptoms appear because of the pa- 
thological waves generated by the afflicted site. When the waves emitted by substances such as medicine or dentures interfere with the pathological waves, the nature of the pathological waves changes and eases bodily discomfort. By considering these points, using the Bi-Digital O-Ring Test [16] [17] can be useful for determining the state of the waves.

The waves changed by the adjustment of the dentures interfered with the waves generated from the afflicted part of the body, and as a result, the symptom may have improved in case 1 and 2 . The pathological waves emitted by the infected first premolar and the right shoulder joint combined to cause her symptoms in case 3. Then, the symptoms improved when the antibiotics were brought close to her face because the pathological waves were interfered with those emitted by the antibiotic. Thus, the form of the pathological wave may have changed. After extracting her premolar, the original pathological waves disappeared, thus eliminating the symptoms.

There are still many unresolved issues in quantum mechanics; for example, the phenomenology of wave function collapse can be described by the many-worlds interpretation [20] or the Copenhagen interpretation [21], but no conclusion has yet been reached. However, by applying body reactions, it may be possible to conclude which interpretation is correct, because almost all studies in physics rely on machines, not bodies.

\section{Conclusion}

Quantum mechanics has a history going back more than 100 years; yet, it has rarely been applied in medicine. Using quantum mechanics, it becomes possible to explain some phenomena observed in clinical practice that cannot be clarified by modern medicine. Quantum mechanics will play an important role in the development of new therapies, and problems that have not been answered yet in the world in quantum mechanics may be solvable using biological reactions. Cooperation between medicine and physics is essential for progress in science.

\section{Conflicts of Interest}

The author declares no conflicts of interest regarding the publication of this paper.

\section{References}

[1] Fujii, Y. (2015) Use of Dental Inlay for Treatment of Hip Joint Dysregulation: A Case Report. Case Reports in Clinical Medicine, 4, 356-360. https://doi.org/10.4236/crcm.2015.411072

[2] Fujii, Y. (2015) Dental Stimulation to the Buccal Mucous Membrane Causes Lumbago: A Report of Two Cases. Case Reports in Clinical Medicine, 4, 289-296. https://doi.org/10.4236/crcm.2015.48058

[3] Fujii, Y. (2016) Improvement of Systemic Symptoms after Dental Implant Removal. Open Journal of Stomatology, 6, 37-46. https://doi.org/10.4236/ojst.2016.62005

[4] Fujii, Y. (2019) Dental Treatment with a Gold Alloy Cast Crown for Severe Lum- 
bago. Open Journal of Stomatology, 9, 21-27.

https://doi.org/10.4236/ojst.2019.92003

[5] Fujii, Y. (2017) Severe Dermatitis Might Be Caused by a Cross-Reaction between Nickel and Palladium and Dental Amalgam Resolved Following Removal of Dental Restorations. Clinical Case Reports, 5, 795-800. https://doi.org/10.1002/ccr3.938

[6] Fujii, Y. (2014) A Case of Non-Allergenic Intractable Dermatitis Likely Caused by Mercury in Dental Amalgams. The Journal of Dentist, 2, 63-66. https://doi.org/10.12974/2311-8695.2014.02.02.4

[7] Fujii, Y. (2012) Do Dental Implants Cause Scoliosis? A Case Report. Personalized Medicine Universe, 1, 79-80. https://doi.org/10.1016/j.pmu.2012.05.012

[8] Fujii, Y. (2014) Sensation of Balance Dysregulation Caused/Aggravated by a Collection of Electromagnetic Waves in a Dental Implant. IEEE Open Journal of Antennas and Propagation, 2, 29-35. https://doi.org/10.4236/ojapr.2014.23004

[9] Fujii, Y. (2014) Gold Alloy Dental Inlay for Preventing Involuntary Body Movements Caused by Electromagnetic Waves Emitted by a Cell Phone. IEEE Open Journal of Antennas and Propagation, 2, 37-43.

https://doi.org/10.4236/ojapr.2014.24005

[10] Fujii, Y. (2015) Dental Treatment for Dizziness and Joint Mobility Disorder Caused by Harmful Electromagnetic Waves. IEEE Open Journal of Antennas and Propagation, 3, 1-7. https://doi.org/10.4236/ojapr.2015.31001

[11] Fujii, Y. (2015) Electromagnetic Waves Collected by a Dental Amalgam Filling Induced Balance Dysregulation and Dizziness over a Period Exceeding 10 Years. Open Journal of Stomatology, 5, 235-242. https://doi.org/10.4236/ojst.2015.510029

[12] Fujii, Y. (2015) Calling into Question the Efficacy of Evidence-Based Medicine: Is It Always the Best Approach? Is That Really the Placebo Effect? Natural Sciences, 7, 165-170. https://doi.org/10.4236/ns.2015.74019

[13] Fein, Y.Y., Geyer, P., Zwick, P., Kiałka, F., Pedalino, S., Mayor, M., Gerlich, S. and Arndt, M. (2019) Quantum Superposition of Molecules beyond $25 \mathrm{kDa}$. Nature Physics, 15, 1242-1245. https://doi.org/10.1038/s41567-019-0663-9

[14] Gustavsson, M., Haller, E., Mark, M.J., Danzl, J.G., Hart, R., Daley, A.J. and Nägerl, H.C. (2010) Interference of Interacting Matter Waves. New Journal of Physics, 12, Article ID: 065029. https://doi.org/10.1088/1367-2630/12/6/065029

[15] Planck, M. (1900) Zur Theorie des Gesetzes der Energieverteilung im Normalspektrum. Verhandlungen, 2, 237-245.

[16] Omura, Y. (1993) Bi-Digital O-Ring Test for Imaging and Diagnosis of Internal Organs of a Patient. US Patent No. 5188107.

[17] Bi-Digital O-Ring Test (BDORT). http://bdort.org

[18] Harrison, A.K. and Flatow, E.L. (2011) Subacromial Impingement Syndrome. The Journal of the American Academy of Orthopaedic Surgeons, 19, 701-708. https://doi.org/10.5435/00124635-201111000-00006

[19] Bigliani, L.U. and Levine, W.N. (1997) Current Concepts Review-Subacromial Impingement Syndrome. The Journal of Bone and Joint Surgery. American Volume, 79, 1854-1868. https://doi.org/10.2106/00004623-199712000-00012

[20] Everett, H. (1957) Relative State Formulation of Quantum Mechanics. Reviews of Modern Physics, 29, 454-462. https://doi.org/10.1103/RevModPhys.29.454

[21] Faye, J. (2008) Copenhagen Interpretation of Quantum Mechanics. Stanford Encyclopedia of Philosophy. https://philpapers.org/rec/FAYCIO 